Gut, 1976, 17, 152-157

\title{
Potassium status of patients with cirrhosis
}

\author{
N. G. SOLER ${ }^{1}$, S. JAIN, H. JAMES, AND A. PATON \\ From the Dudley Road Hospital, Birmingham, and the Department of Experimental Pathology, \\ University of Birmingham
}

SUMMARY Whole body potassium measurements were performed on 55 cirrhotic patients in different stages of the disease. They included 34 with alcoholic cirrhosis, 10 with cryptogenic cirrhosis, eight with chronic active hepatitis, and three with haemochromatosis. Serial measurements were carried out in 21 patients. The findings of this study indicate that: (1) the aetiology of the cirrhosis is important in determining the potassium status of cirrhotics, most alcoholics being depleted; (2) ascites and decompensation are usually associated with potassium depletion but compensated cirrhotics may also be depleted even when not receiving diuretics; (3) the initial potassium status, whether a cirrhotic be decompensated or not, is difficult to alter in the short term (six months). Marked changes in potassium status can occur in alcoholic patients studied over longer periods.

Potassium status is important because it influences general well being through its physiological effects on muscle contractibility and cardiac function, on hydrogen ion exchange in the tubules and acid base balance, and on insulin secretion. Several factors including diet, gastrointestinal losses, and diuretic treatment may affect adversely the potassium status of cirrhotic patients. Studies using exchangeable potassium $\left({ }^{42} \mathrm{~K}\right)$ have shown that cirrhotics, even without oedema or ascites, may be depleted of total body potassium in the presence of a normal serum potassium (Aikawa et al., 1953; Burrows et al., 1953). Other workers have also concluded that serum potassium determinations are poor indicators of body potassium stores in patients with cirrhosis (Heinemann and Emirgil, 1960; Case et al., 1965). While exchageable potassium is often decreased in cirrhotics (Aikawa et al., 1953; Kukral et al., 1969), this is not an invariable finding (Casey et al., 1965) and it is not clear whether patients with different types of cirrhosis are affected to the same extent. Casey et al. (1961) reported that the more severe the liver disease the lower the body potassium stores, and it has been suggested that patients with severely impaired liver function may be unable to retain potassium supplements (Aikawa et al., 1953; Heinemann and Emirgil, 1960; Case et al., 1965).

The whole body counter can be used to study whole body potassium in large groups of patients, including those with cirrhosis, with minimal dis-

${ }^{1}$ Address for correspondence: Dr. N. G. Soler, Postgraduate Centre, Dudley Road Hospital, Birmingham, England.

Received for publication 10 December 1975 comfort. Repeated measurements can be performed either at frequent intervals to study short-term fluctuations or at longer intervals to observe changes which may reflect the natural progression of the disease or the response to treatment. The aims of the present study were: (1) to investigate potassium status in relation to different aetiological types of cirrhosis; (2) to study the influence of factors such as decompensation, carbohydrate intolerance, and diuretic treatment on potassium status; and (3) to detect both acute and long-term changes in whole body potassium by serial measurements and to relate them to the clinical condition and management of patients with cirrhosis.

\section{Methods}

\section{PATIENTS}

Fifty-five patients were studied: 34 with alcoholic cirrhosis, 10 with cryptogenic cirrhosis, eight with chronic active hepatitis, and three with haemochromatosis. There were 36 men and 19 women ranging in age from 19 to 65 years. Diagnosis was based on the usual clinicopathological features confirmed by liver biopsy. Patients were in different stages of the disease (Table) and the clinical condition varied from fully compensated to decompensated with one or more features of jaundice, ascites, or hepatic encephalopathy.

All patients had an initial whole body potassium measurement. Sequential studies were carried out if the patient remained alive and continued to attend hospital: 21 patients were studied in this way. 


\begin{tabular}{|c|c|c|c|c|c|c|}
\hline \multirow[t]{2}{*}{ Cirrhosis } & \multirow{2}{*}{$\begin{array}{l}\text { Male } \\
\text { (no.) }\end{array}$} & \multirow{2}{*}{$\begin{array}{l}\text { Female } \\
\text { (no.) }\end{array}$} & \multicolumn{2}{|c|}{ Complications } & \multirow{2}{*}{$\begin{array}{l}\text { Treatment } \\
\text {-with } \\
\text { diuretics }\end{array}$} & \multirow[t]{2}{*}{ Diabetes } \\
\hline & & & Ascit & $\begin{array}{l}\text { Jaundice } \\
\text { or } \\
\text { pre-coma }\end{array}$ & & \\
\hline \multirow{4}{*}{$\begin{array}{l}\text { Alcoholic } \\
\text { Cryptogenic } \\
\text { Chronic active } \\
\text { hepatitis } \\
\text { Haemochroma- } \\
\text { tosis }\end{array}$} & 26 & 8 & 11 & 8 & 12 & 6 \\
\hline & 6 & 4 & 2 & 4 & 5 & 1 \\
\hline & 1 & 7 & 0 & 2 & 1 & 1 \\
\hline & 3 & 0 & 0 & 0 & 0 & 3 \\
\hline
\end{tabular}

Table Clinical data on 55 patients with cirrhosis

Whole body potassium was measured by detecting naturally occurring ${ }^{40} \mathrm{~K}$ in a whole body counter. The counter had been calibrated using standard techniques (Hughes and Williams, 1967). Random errors in counting and the error in the use of the calibration curve accounted for between $2.9 \%$ and $4.2 \%$ (one coefficient of variation). The normal whole body potassium had already been established in this laboratory for 111 healthy men and women of different body builds and ages ( $\mathrm{H}$. James, unpublished). The best correlation between measured whole body potassium and body build was obtained by applying least square analysis to the following equation:

Whole body potassium $(\mathrm{g})=\mathrm{a} \times$ weight $(\mathrm{kg})+$ $\mathrm{b} \times$ total fat $(\mathrm{kg})+\mathrm{c} \times$ height $^{2}\left(\mathrm{~m}^{2}\right)+$ shoulder width $(\mathrm{m})+\mathrm{d}$

The values obtained for the constants $a, b, c$ and $d$ are shown below:

$$
\begin{array}{lcccc} 
& \mathrm{a} & \mathrm{b} & \mathrm{c} & \mathrm{d} \\
56 \text { men } & +1.29 & -1.26 & +61.5 & -4.4 \\
55 \text { women } & +1.06 & -0.47 & +31.0 & +13.9
\end{array}
$$

When a patient's body measurements are inserted in the equation an estimate of the expected normal whole body potassium $(\mathrm{Ke})$ is obtained and the observed whole body potassium (Ko) can be compared with this value $(\mathrm{Ko} / \mathrm{Ke})$. In the control group, the mean $\mathrm{Ko} / \mathrm{Ke}$ was by definition $1 \cdot 00$, the range being $0 \cdot 84-1 \cdot 16( \pm 2$ standard deviations) and there was no significant change in $\mathrm{Ko} / \mathrm{Ke}$ with age. The use of $\mathrm{Ko} / \mathrm{Ke}$ to express potassium status allows a comparison of the same individual at different times, taking into consideration his changing body build. Comparisons between individuals of both sexes also become possible.

Total body fat was measured using skinfold calipers according to the method described by Fletcher (1962).

\section{Results}

The initial whole body potassium readings were expressed as the ratio of observed whole body potassium (Ko) to the normal whole body potassium expected for body size (Ke). Patients were equally divided between those within the normal range $(0 \cdot 84-1 \cdot 16)$ and the rest who were significantly depleted (Fig. 1). However, differences emerged between the various forms of cirrhosis. Twenty-three of the 34 patients with alcoholic cirrhosis were significantly depleted and in 16 the depletion was greater $(\mathrm{Ko} / \mathrm{Ke}<0.76)$ than in any other patient. On the other hand, the $\mathrm{Ko} / \mathrm{Ke}$ was within the normal range in all eight patients with chronic active hepatitis, while patients with cryptogenic cirrhosis occupied an intermediate position, exactly half being normal. One patient with haemochromatosis was significantly depleted while the other two were normal.

The expected whole body potassium $(\mathrm{Ke})$ is partly based on the patient's weight so that 13 patients with fluid retention (Table) may have had a falsely low $\mathrm{Ko} / \mathrm{Ke}$ ratio. However, recalculation, allowing for 5 litres of fluid retention in patients with mild ascites and for 10 litres of fluid in patients with more severe ascites does not significantly alter the $\mathrm{Ko} / \mathrm{Ke}$ distribution of patients within the different forms of cirrhosis.

The pattern of $\mathrm{Ko} / \mathrm{Ke}$ differs in the alcoholic from that in other types of cirrhosis (Fig. 1). Patients with cryptogenic cirrhosis, chronic active hepatitis, and haemochromatosis have therefore been grouped together and compared with alcoholics with respect to factors which may affect potassium balance such as fluid retention, treatment with diuretics, hepatic decompensation, and diabetes (Fig. 2). All patients with ascites were depleted of potassium but approximately half those with potassium depletion did not have ascites. Among the 13 patients with ascites only eight were on diuretic treatment when their whole body potassium was measured. Treatment with diuretics was not necessarily associated with potassium depletion and only six of the 16 most severely depleted patients were receiving diuretics (Fig. 2). A variety of diuretics were used: of the 12 patients on diuretics who were depleted of potassium, six were taking frusemide and the rest chlorothiazide. In addition, seven of these patients were prescribed aldactone and potassium supplements, four aldactone, and a single patient potassium supplements alone. Among the six cirrhotics on diuretic treatment who were not depleted of potassium, four were receiving frusemide and two chlorothiazide. All these patients were on potassium supplements and two of them were also taking aldactone. The duration of diuretic therapy was not noticeably different between cirrhotics who were depleted of potassium and the rest who maintained normal body potassium stores. Although decompensation was more likely to be 


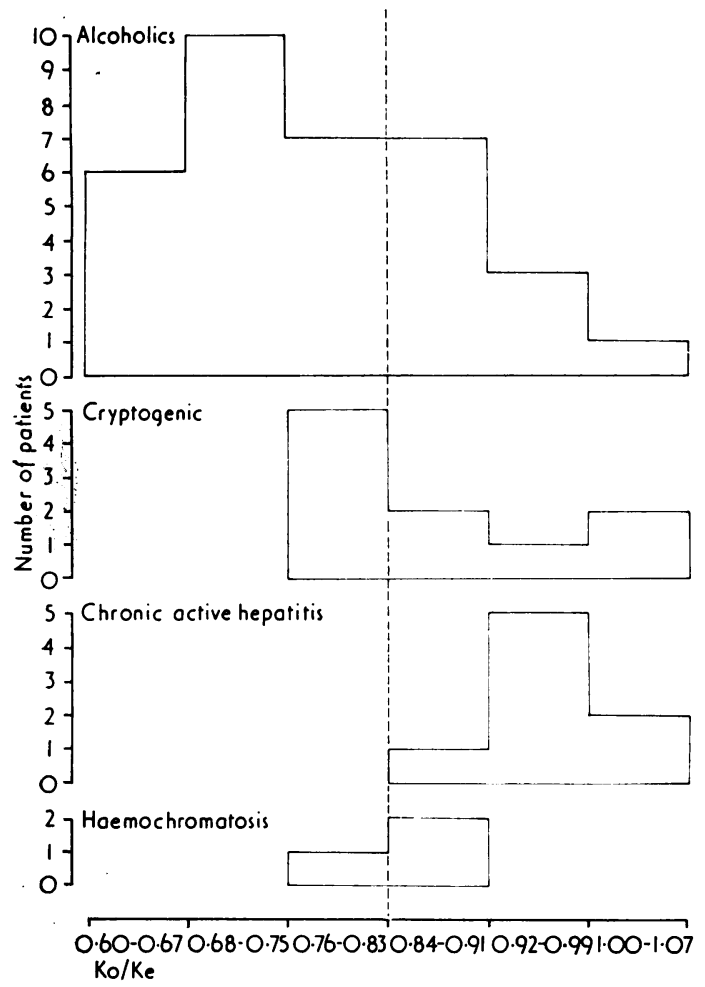

Fig. 1 The whole body potassium (Ko/Ke) distribution of patients with cirrhosis of different aetiologies.

$\mathrm{Ko} / \mathrm{Ke}$ values of 0.84 and above are normal, while values below 0.84 indicate potassium depletion. associated with potassium depletion, this was not always so (Fig. 2). Diabetes requiring treatment with oral therapy or insulin was spread equally between patients with and without significant potassium depletion (Fig. 2).

The relationship between whole body potassium expressed as $\mathrm{Ko} / \mathrm{Ke}$ and the serum potassium is shown in Fig. 3. The majority of patients had serum potassium determinations at the time the initial whole body potassium was measured but later readings, when available, are also included. Patients on treatment with diuretics, potassium supplements, or corticosteroids have been separated from the rest. Serum potassium readings of $<3.5 \mathrm{mmol} / 1$ were invariably associated with a low whole body potassium $(\mathrm{Ko} / \mathrm{Ke}<0.84)$ but patients with a depleted whole body potassium often had a serum potassium within the normal range independent of whether they were receiving treatment or not.

\section{SERIAL STUDIES}

Short-term studies of whole body potassium were carried out in 14 patients who had serial measurements during a period of six months or less (Fig. 4a). The first measurements were recorded at the time of presentation in most cases, but in three patients later on. Eight patients were initially depleted of potassium and six had a normal $\mathrm{Ko} / \mathrm{Ke}$. Compensated and decompensated cirrhotics were equally represented among patients with and without potassium depletion. All patients with low body

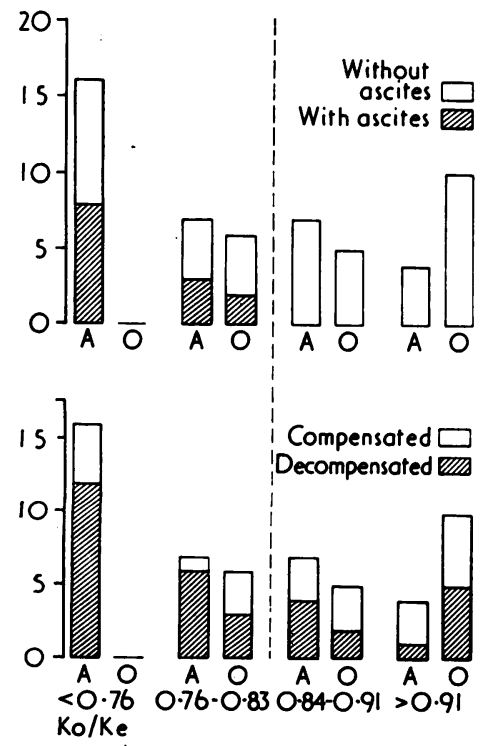

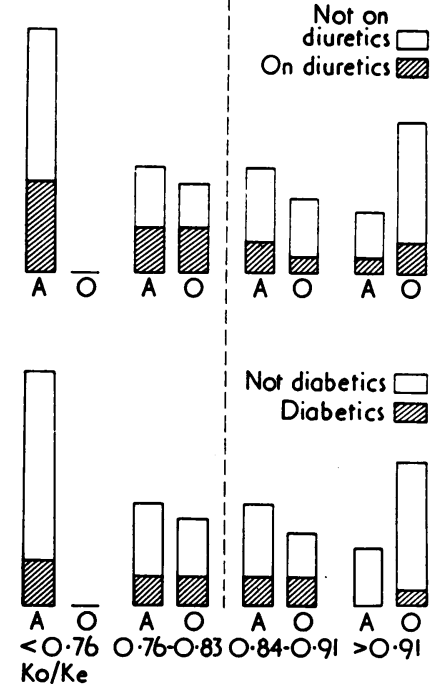

Fig. 2 The whole body potassium $(\mathrm{Ko} / \mathrm{Ke})$ distribution of patients with alcoholic cirrhosis $(A)$ and of patients with other forms of cirrhosis $(O)$ in relation to ascites, decompensation, treatment with diuretics, and diabetes. $\mathrm{Ko} / \mathrm{Ke}$ values of 0.84 and above are normal, while values below 0.84 indicate potassium depletion. 


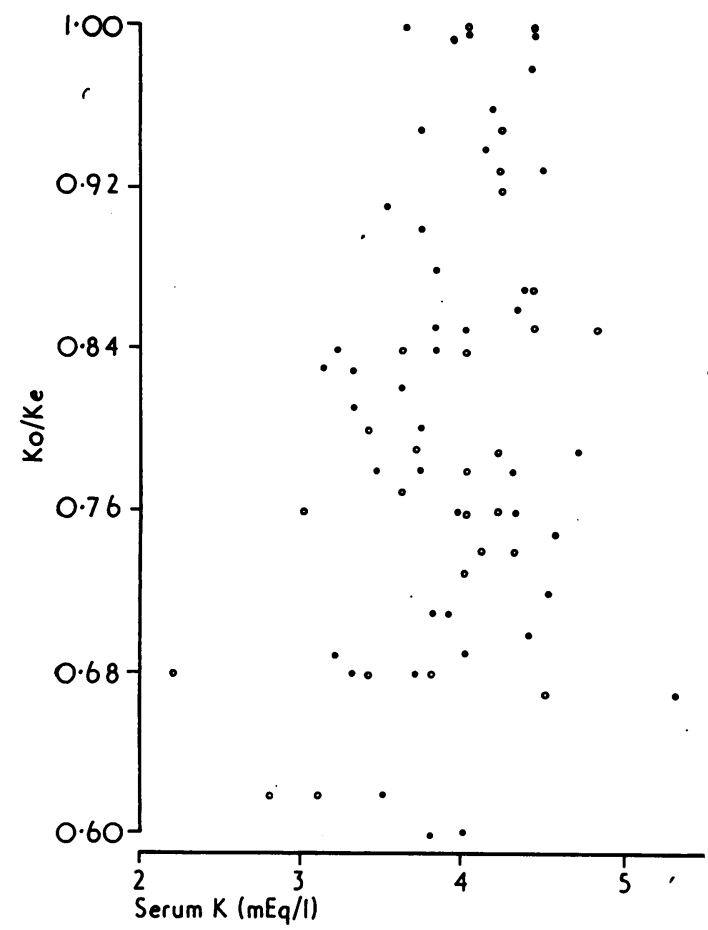

Fig. 3 The relationship of the serum potassium to the whole body potassium $(\mathrm{Ko} / \mathrm{Ke})$ in untreated and treated cirrhotics. : no treatment $\bigcirc$ : on treatment.

potassium stores were given potassium supplements and half of them were also receiving diuretics (frusemide with spironolactone). In only one patient did the $\mathrm{Ko} / \mathrm{Ke}$ ratio change to the normal range over the course of six months. Among the six patients with a normal whole body potassium, two needed diuretic treatment and were also receiving potassium supplements, a third patient was given corticosteroids, and the remaining three were not on any treatment. The $\mathrm{Ko} / \mathrm{Ke}$ remained normal in all cases.

Long-term studies of up to three years were also performed, on 17 patients (Fig. 4b). Two of six cirrhotics who were initially depleted of potassium changed to a normal $\mathrm{Ko} / \mathrm{Ke}$ : one appeared to be compensated throughout the period of observation, while the other had episodes of decompensation and was receiving diuretics and potassium supplements. Of the four patients who remained depleted of potassium, two were always compensated and did not require treatment. The 11 patients with an initially normal $\mathrm{Ko} / \mathrm{Ke}$ included compensated as well as decompensated cirrhotics requiring various forms of treatment, but only two became depleted during the course of the study. The fall in whole body

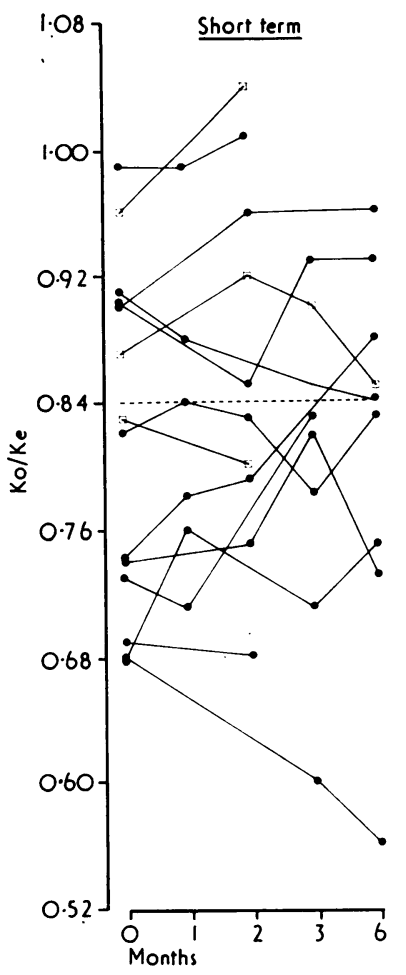

(a)

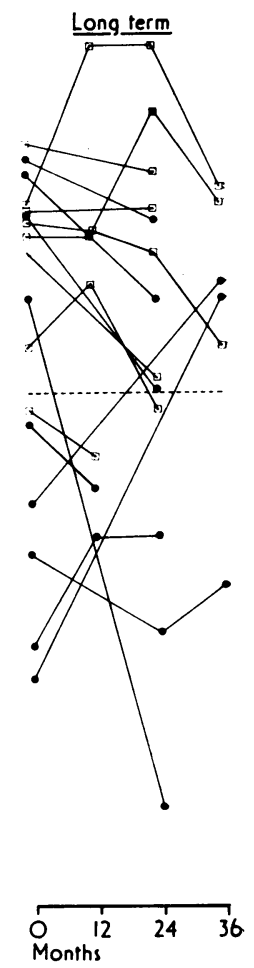

(b)
Fig. 4 Serial studies of whole body potassium (Ko/Ke) in patients with alcoholic cirrhosis and in patients with other forms of cirrhosis. Short-term studies $(a)$ covered a period of six months and long-term studies $(b)$ covered a period of 12 months or more. Ko/Ke values above 0.84 are normal while values below 0.84 indicate potassium depletion. O: alcoholic, $\square$ : others.

potassium in one case remains unexplained, although it appears that the patient continued to drink heavily while under study. The other patient who had cryptogenic cirrhosis had been subjected to a portacaval shunt and was on a low protein diet.

It may be argued that the changes in whole body potassium observed during the short-term and long-term studies may have been determined by changes in lean body mass (body weight-total body fat) but this is not borne out by our findings (Fig. 5). Consecutive readings of whole body potassium which were significantly different $(95 \%$ confidence limits) have been related to changes in lean body mass observed during the same period of time. Clearly the majority of increases and decreases of whole body potassium occurred independently of changes in lean body mass. In half our patients total body nitrogen using neutron activation analysis 


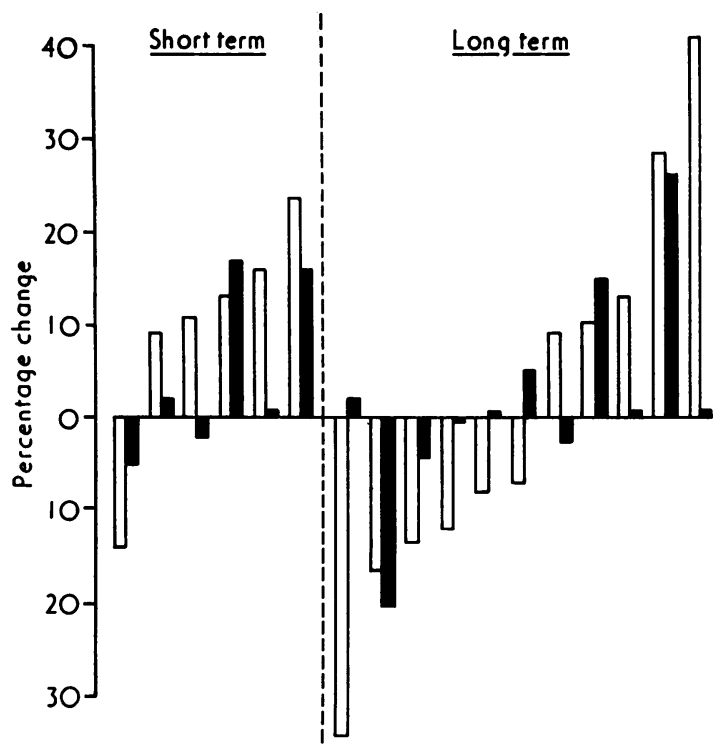

Fig. 5 The change in whole body potassium related to the change in lean body mass observed during the same period of time in patients who had a significant change in whole body potassium. $\square$ : whole body potassium; : lean body mass.

(Harvey et al., 1973) was studied at the same time and the results, which will be the subject of a later report, confirm the present findings.

\section{Discussion}

Cirrhotic patients are not always depleted of whole body potassium according to our studies. The aetiology of the cirrhosis is important in this respect, the majority of alcoholics being depleted while patients with chronic active hepatitis have normal body potassium stores. On the other hand, patients with cryptogenic cirrhosis may also be depleted but their potassium deficit is not as severe as seen in some of the patients with alcoholic cirrhosis. Although a serum potassium below the normal range usually indicates a low whole body potassium, serum potassium determinations may be misleading, normal values occurring in cirrhotics with and without potassium depletion.

Various factors influence the potassium status of cirrhotic patients. Decompensated patients in general tend to have low body potassium stores but it is only patients with ascites who are invariably depleted of potassium. One-third of the patients receiving treatment with diuretics (together with potassium supplements) managed to maintain a normal whole body potassium and, although the rest were depleted, it is difficult to separate the effect of diuretics from that of the underlying decompensated liver disease. Similarly, there was no clear separation between the effects of different diuretic regimens on potassium status. Diabetes needing treatment with oral hypoglycaemic drugs or insulin was not a significant factor in the potassium depletion encountered in this series. However, uncontrolled diabetes can lead to potassium depletion (Walsh et al., 1974) and probably explains the significant depletion of a single patient with haemochromatosis who had recovered from a episode of ketoacidosis only a few weeks previously.

When the potassium status of fully compensated patients not receiving diuretics is considered, it emerges that eight out of 22 were also significantly depleted of potassium; these included five out of 11 patients with alcoholic cirrhosis and three out of 11 patients with other forms of cirrhosis, a distribution of potassium depletion not dissimilar to that recorded for the series as a whole. These findings suggest that in the natural course of cirrhosis other factors also play a part in potassium depletion, and one or more factors may account for the more frequent and severe depletion of patients with alcoholic cirrhosis. Ellis et al. (1974) have reported low whole body potassium stores in alcoholics who were not necessarily cirrhotic. Dietary intake of potassium, gastrointestinal losses, hyperaldosteronism, renal tubular damage, and possibly a diuretic effect of alcohol may all be implicated, and these factors are the subject of further study.

It has been suggested that patients with severe liver disease are unable to retain potassium supplements (Aikawa et al., 1953; Heinemann and Emirgil, 1960; Casey et al., 1965) but in our study both compensated and decompensated patients with potassium depletion (with one exception) failed to attain a normal whole body potassium within six months. The lack of response to treatment with potassium supplements may to a certain extent be explained by the concurrent use of diuretics in half the cases, but, even so, potassium-losing diuretics were used in conjunction with potassium-sparing diuretics. Of the seven patients with a persistently low $\mathrm{Ko} / \mathrm{Ke}$, two died within a few months, a third was lost to follow-up but survived for another three years, and the rest have been followed-up for at least two years and are still depleted of potassium. In contrast, all patients with an initially normal whole body potassium maintained this potassium status, at least in the short term, despite the use of diuretics or corticosteroids. One can only conclude that treatment is singularly ineffective in changing the potassium status of cirrhotics either way over the course of a few months.

However, long-term studies indicate that cirrhotic patients can alter their potassium status, although in 
our series this change was confined to four out of 17 patients studied. While two out of nine alcoholic patients changed from a depleted to a normal whole body potassium, a third became seriously depleted after an initially normal whole body potassium. On the other hand, of three patients with cryptogenic cirrhosis, one was depleted and another had a normal whole body potassium throughout the period of observation, while a third patient developed a low whole body potassium after a portacaval shunt. Although some significant changes in whole body potassium were noted in individual patients with chronic active hepatitis in decompensated stages, this form of cirrhosis was always associated with a whole body potassium within the normal range in the five patients studied.

Casey et al. (1965) concluded that depletion of potassium had relatively little influence on clinical and biochemical changes in hepatic coma. In our own experience, seven patients who were studied only a few weeks before they died in hepatic coma all had a low whole body potassium. On the other hand, other cirrhotics have survived for over three years with depleted body potassium stores. Of the latter patients, some have appeared to be compensated throughout, while others have experienced episodes of decompensation. The clinical and prognostic significance of a low whole body potassium in patients with cirrhosis remains a matter for debate.

\section{References}

Aikawa, J. K., Felts, J. H., and Harrell, G. T. (1953). Alterations in the body potassium content in cirrhosis of the liver. Gastroenterology, 24, 437-443.
Burrows, B., Denton, J., Ferguson, B., and Ross, J. (1953). Changes in body potassium in hepatic decompensation. Clinical Research Proceedings, 1, 111.

Casey, T. H., Summerskill, W. H. J., and Orvis, A. L. (1961). Disorders of potassium metabolism in liver disease. Journal of Clinical Investigation, 40, 1028-1029.

Casey, T. H., Summerskill, W. H. J., and Orvis, A. L. (1965). Body and serum potassium in liver disease. I. Relationship to hepatic function and associated factors. Gastroenterology, 48, 198-207.

Casey, T. H., Summerskill, W. H. J., Bickford, R. G., and Rosevear, J. W. (1965). Body and serum potassium in liver disease. II Relationship to arterial ammonia, blood pH, and hepatic coma. Gastroenterology, 48, 208-215.

Ellis, K. J., Shukla, K. K., Cohn, S. H., and Pierson, R. N. (1974). A predictor for total body potassium in man based on height, weight, sex, and age: applications in metabolic disorders. Journal of Laboratory and Clinical Medicine, 83, 716-727.

Fletcher, R. F. (1962). The measurement of total body fat with skinfold calipers. Clinical Science, 22, 333-346.

Harvey, T. C., Jain, S., Dykes, P. W., James, H., Chen, N. S., Chettle, D. R., Ettinger, K. V., Fremlin, J. H., and Thomas, B. J. (1973). Measurement of whole-body nitrogen by neutron-activation analysis. Lancet, 2, 395399.

Heinemann, H. O., and Emirgil, C. (1960). Hypokalemia in liver disease. Metabolism, 9, 869-879.

Hughes, D., and Williams, R. E. (1967). The calibration of a whole-body radioactivity counter for the measurement of body potassium content in clinical studies. Clinical Science, 32, 495-502.

Kukral, J. C., Brandly, J. M., Fritsch, B. A., Stefanovic, N., and Henegar, G. C. (1969). Total body composition in cirrhotic patients with metabolic alkalosis, hypokalemia, hyperammoniemia and portacaval shunt. American Journal of Surgery, 117, 85-90.

Walsh, C. H., Soler, N. G., James, H., Fitzgerald, M. G., and Malins, J. M. (1974). Studies on whole-body potassium in non-ketoacidotic diabetics before and after treatment. British Medical Journal, 4, 738-740. 